\title{
QUALITY ASSURANCE IN A REHABILITATION SERVICE
}

\begin{abstract}
Aim: The aim of this study was to develop, implement and evaluate a Quality Assurance ( $Q A)$ programme for use by nine rehabilitation departments in the Midlands province of Zimbabwe.

Methodology: A participatory methodology was implemented to:

1. Define and implement the parameters of quality for a rehabilitation service.

2. Design standardised assessment forms for the different conditions managed.

\section{MYEZWA H, MCSP';

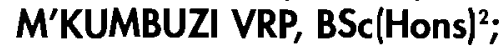 MHURI F, BSc(Hons) ${ }^{2}$}

${ }_{2}^{1}$ Regional Co-ordinator, GIZ-Health Systems Research
${ }^{2}$ Faculty of Medicine, University of Zimbabwe

3. Develop, pilot and evaluate a QA measuring instrument to use in defining the QA profile of a rehabilitation service, and

4. Determine patient satisfaction with the rehabilitation service. Administering a simple questionnaire, whose design was based on the Zimbabwe Patients Charter, accomplished this.
\end{abstract}

Results: The process of developing, implementing and evaluation of the QA programme took six years. One year after implementation of the $Q A$, all $(100 \%)$ patients coming into contact with the service had a rehabilitation record. The QA profile for the Midlands province rose from 55\% in 1994 to a record high of 92.1\% in 1998, and 89.4\% in 1999. The patient satisfaction profile for each indicator also demonstrated a linear increase with areas such as satisfaction with service rising from $86 \%$ in 1997 to $100 \%$ in 2000, and satisfaction with benefit from the service rising from $76.6 \%$ in 1997 to 100\% in 2000. Other qualitative benefits not depicted by the QA measuring instrument or the patient satisfaction instrument, but which were observed and expressed by rehabilitation staff as measures of success of the QA programme are discussed.

Conclusion: This paper concludes that significant improvements in clinical documentation arising from the $Q A$ programme, translated to an overall increase in the service providers' professional skills and knowledge base, and ultimately rehabilitation outcomes. The success of this process is attributed to its participatory and empowering nature.

\section{KEY WORDS: QUALITY ASSURANCE, REHABILITATION SERVICE.}

\section{INTRODUCTION}

The Midlands province is one of eight provinces in Zimbabwe and has a population of 1.3 million (Central Statistics Office, 1998). Gweru is the provincial capital of the Midlands province and is situated $300 \mathrm{~km}$ southwest of Harare, the capital city of Zimbabwe. The Midlands province is made up of eight administrative districts. Of these, Gweru and Kwekwe are two of the five large cities found in Zimbabwe and are largely urban. The remaining districts are Gokwe North, Gokwe South, Mvuma, Mberengwa, Zvishavane and Shurugwi have largely rural populations.

The rehabilitation service described here is set principally in the Gweru district in the Midlands province of Zimbabwe, but was subsequently extended to the remaining eight districts in the Midlands province. Gweru Provincial Hospital is a 300-bed, referral hospital with a bed occupancy rate of
94.5\% (Midlands Annual Profile, 1997). The Midlands annual profile (1997) established the daily attendance rate as 224.7. Ancillary departments servicing the hospital include radiology, occupational therapy, physiotherapy, rehabilitation, dentistry and ophthalmology.

\section{Rehabilitation Service Delivery Development} In 1980 the rehabilitation department was one of the newest departments in the hospital, staffed by one therapist, who was subsequently joined by three rehabilitation technicians. Between 1980 and 1987 initiatives were taken to establish and develop the rehabilitation service.

By 1990 the department was running the following services:

- In and out patient services

- Outreach services

- Community based rehabilitation services
Rehabilitation here includes the provision of occupational therapy, physiotherapy, speech therapy and rehabilitation services.

In all these areas, the rehabilitation department in Gweru Hospital was the nucleus for activity. It functioned as a referral and facilitation centre for the Midlands province, and as such had to be exemplary in all its functions. Eight new departments situated in districts within the Midlands province were opened under the guidance of the Gweru Provincial Rehabilitation department and the provincial therapist. In addition to developing rehabilitation services,

\section{CORRESPONDENCE TO:}

H Myezwa

PO Box 2406, Harare, Zimbabwe Tel: +263-4-733696, Fax: +263-4-733695 Email: gtz-hsr@internet.co.zw 
the core function of the Gweru department remained that of supporting the clinical work.

\section{Quality Assurance (QA)}

Quality assurance is ".....all the processes and sub-processes of planning for quality, the development of objectives for quality, setting standards (including guidelines, policies, protocols etc), actively communicating standards, developing indicators, setting thresholds, collecting data to monitor compliance to standards and applying solutions to improve healthcare" (Paeger, 1997). Quality assurance in the health field is a "process where the ultimate objective is to improve the outcome of all healthcares, functional ability, patient well-being and consumer satisfaction" (Reerink, 1999). Quality assurance is driven by "customer demands, financial burdens and professional demand for quality" (Blumenthal, 1997). Health services in general, and rehabilitation services in particular are no exception to the growing need and recognition of QA.

\section{Statement of the Problem}

An annual performance review conducted in the Midlands province for all eight districts, in 1993 revealed that one of the major problems was the varied quality of clinical work. This was attributed to:

a) The different cadres providing the service - physiotherapists, occupational therapists, rehabilitation technicians and orthopaedic technologists;

b) Their varied training backgrounds and

c) A lack of standardisation of clinical procedures.

To resolve this anomaly a quality assurance programme for improving and ensuring high quality patient management was commenced.

\section{Quality Assurance Development}

A three-step process commencing in 1993 was undertaken in order to formulate the objectives of the QA programme. These were as follows:

1. Introduction of the quality assurance approach to all staff members.

2. Identification of problems in patient management using the problem analysis method - Objective Programme Planning (ZOPP - GTZ, 1992). The ZOPP analysis elicited the following problems:

- Non-standardised approach to clients

- Poor recording of assessment, treatment, results and outcomes

- Poor treatment outcomes

- Poor perception of services by clients

- High non return rate of clients

- High turnover of staff resulting in a lack of consistency.

3. Once staff understood the methodology in implementing QA, they formulated the following objectives for the QA programme:

- To design standardised assessment forms for the different conditions managed

- To ensure that every client undergoes an assessment

- To ensure consistent recording of information in agreed categories

- To ensure that all clients visits are recorded and followed up.

- To obtain the clients views on the quality of service

\section{METHODOLOGY \\ Participants:}

The ZOPP was conducted during the Midlands annual planning meeting. Each district in the province is represented at this meeting. Participants were therefore drawn from each rehabilitation department in the province and constituted 5 therapists and 16 rehabilitation technicians.

Participants engaged in brainstorming sessions and group discussions. Based on their professional opinions and experiences on areas of breakdown in patient management, participants agreed on the areas for QA as:

- The need to make a record for each client attending rehabilitation

- The need to ensure a high degree of completion of each patient record

- The need to ensure a high level of patient satisfaction with the service provided by the rehabilitation department.

Further, it was agreed that the patient record should contain the following categories:
- Demographic data

- Assessment findings

- Problem list

- Treatment plan

- Progress notes

- Reassessment where needed.

The procedure for carrying out the programme was as follows:

A peer review group was convened every three months and a review schedule set up. Each member of staff was involved. The peer review group assessed each record for new patients seen during the quarter under review. The assessment involved allocating a percentage to the degree of completion on an agreed rating schedule. A mean for the department per quarter and per annum was then calculated to obtain a QA status. A report was compiled, and each member of staff received feedback on the strengths and weaknesses of their recordings.

Only one or two rehabilitation staff manned all districts. In such instances support was made available by borrowing staff from other districts around the province to conduct the peer review. One such district - Mberengwa benefited from this arrangement, but on the whole it enabled the QA programme to develop at a relatively equal pace in all districts and subsequently to define a provincial QA status.

Finally, a standard questionnaire was developed to provide feedback on clients' perception of the quality of the rehabilitation service. This questionnaire was administered to all new clients for a period of three months.

\section{Process of Developing the QA Instrument}

Two major sources of expertise were used to establish a rating scale for the completion of the physiotherapy record.

A review of the literature (McRae, 1983; Cash, 1984) facilitated a definition of the sections that were considered an essential part of the physiotherapy record and needed to be included. It also became evident that the objective and physical examination was the most important part of the physiotherapy record in terms of determining progress and outcome, as well as assisting in the monitoring. 
The second source was based on participants' professional opinions. A Delphi approach was used to define sections of the record most commonly rated highly. Such factors as; where staff felt the greatest proportion of their time in assessment lay, as well as aspects of the record that might improve the wider application of their work were put forward as justification for rating of the sections. For instance, initially participants justified a high rating for demographic data because of the problems they experienced in following up patients.

It was noted that the high weighting given by the staff for the different areas recorded such as demographic data and assessment findings were consistent with the literature. For example, the assessment findings and problem list were important for the clinical outcome, hence these were rated highest. The categories of assessment were thus defined and rated as follows:

- Demographic data:

- Assessment findings \& problem list:

- Treatment plan \& progress notes:

- Reassessment and discharge notes (where applicable): To formulate standardised assessment forms, participants engaged in a consensus building process for all categories of patients managed, within the department. Thus, standardised assessment forms were developed for orthopaedic, adult neurology, paediatric neurology, general paediatric, general adult and psychiatry conditions.

\section{Pilot of the QA Instrument}

Prior to the introduction of the QA programme, not all patients had an assessment record filled out. The practice in the department at the time was to complete rehabilitation records for patients with chronic conditions such as cerebral palsy and cerebrovascular accident. All other patient categories had no specific rehabilitation record, or had a rehabilitation progress summary written in the medical record.

After implementation of the QA programme all $(100 \%)$ patients had a rehabilitation record.
This first draft of the QA instrument was piloted in Gweru. The QA results obtained are shown in Table 1.

TABLE 1. Gweru Rehabilitation Department - QA Status 1994 - 1996.

\begin{tabular}{|c|c|c|}
\hline & Number of Patient Records Reviewed & QAStatus \\
\hline 1994 & 2159 & $55 \%$ \\
\hline 1995 & 2680 & $75 \%$ \\
\hline 1996 & 2723 & $75.2 \%$ \\
\hline
\end{tabular}

A linear increase in the degree of completion was observed from inception of the QA programme to 1996. During this time the number of records with a higher degree of completion and more categories (such as demographics, assessment findings etc.) filled in, increased. The problem of follow up diminished with the improvement in recording of patient demographics.

\section{Review of the QA Instrument}

After three years of use of the QA instrument, rehabilitation staff expressed the need to review the QA instrument.

This need was mainly borne out of a realisation that the initial problems in quality assurance within the province had been dealt with i.e. a) Each client now had an assessment and treatment record and b) the problem of following up patients had improved significantly. Staff felt that the programme should now focus on a new set of quality problems.

Hence during brainstorming and problem solving sessions, staff indicated that in the process of improving the degree of completion of the patient record, they had identified their areas of clinical weakness. This enabled the planning and execution of relevant and specific in-service training. Subsequently, the effort and quality of clinical assessment and recording improved and staff members found the current QA ratings now inappropriate. They expressed the need thus to:

1. Increase the assessment findings and problem list allocation and rating and

2. To further desegregate the categories so as to improve the sensitivity of the instrument.

Staff members found they were spending more time on the physical assessment and said they could see the direct benefit of this process to clinical outcomes and patient satisfaction. This new shift in focus reflected a move from concern with clerical type recording to clinical data recording and staff could more easily translate the importance of the rehabilitation record to clinical outcomes.

As a result the review came up with new ratings outlined in Table 2.

TABLE 2. Post - Review QA Ratings Per Assessment Category

\begin{tabular}{|l|c|}
\hline Demographic data & $15 \%$ \\
\hline Past and present medical and social history & $15 \%$ \\
\hline Assessment findings and problem list & $50 \%$ \\
\hline Treatment aims and plan & $10 \%$ \\
\hline Progress. notes & $10 \%$ \\
\hline
\end{tabular}

After the review the new instrument was used first in Gweru district alone, and then in the other eight districts in the Midlands province to obtain a provincial QA profile.

TABLE 3. Gweru QA Status after the QA Instrument Review 1997 - 1999.

\begin{tabular}{|c|c|c|}
\hline & Number of Patient Records Reviewed & QAStatus \\
\hline 1994 & 2688 & $90 \%$ \\
\hline 1998 & 2876 & $91.2 \%$ \\
\hline 1999 & 2064 & $89.4 \%$ \\
\hline
\end{tabular}


The QA status rose by over a 15\% margin between 1996 and 1998. It became evident that a sense of ownership of the programme had taken root. The value of QA was now more readily accepted and appreciated, as one member of staff commented, "I now see that it is not a witch hunt."

The decrease in patient records in 1999 is attributed to the introduction of user fees. This saw a fall in the number of patients attending rehabilitation. The marginal drop in the QA status also evident in 1999 is attributed to a loss and change of rehabilitation staff including the substantive provincial therapist through whose office most QA monitoring was planned and directed. (See Table 3.)

\section{FIGURE I. Midlands Q.A. Status 1995-1998}

The average Quality Assurance status for the province was calculated at the end of each year as part of the annual report. All eight districts with operational rehabilitation departments were included and the total number of records reviewed in 1994 was 638I while the average for 1995-1999 was 8565. (See Figure 1.)

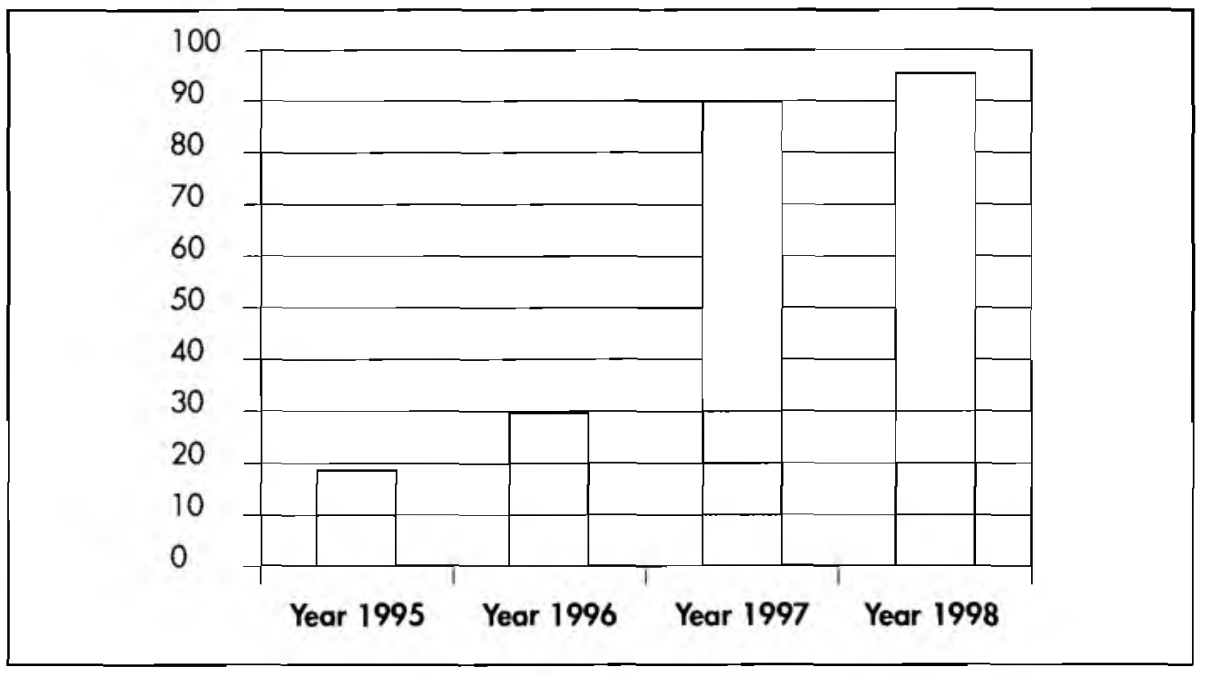

\section{Patient Satisfaction}

Patient satisfaction was considered an important component of the quality assurance programme. The client's perception and view of the service and its delivery were sought.

\section{Methodology}

For 3 months of the year (first quarter = January to March), each new patient attending rehabilitation was asked to fill in a questionnaire or interviewed to determine the satisfaction with the rehabilitation service. The simple question- naire was made available in English, Shona and Ndebele, and was based on the Zimbabwe Patients Charter. This charter describes the rights of patients and the obligations of health service providers to patients.

Thus indicators of satisfaction were defined as:

- Waiting time

- Availability of information e.g. Explanation of diagnosis, treatment etc.

- Reception - Friendliness of staff

- General satisfaction with service

- Areas that clients felt need improvement
Two QA areas which clients constantly identified as needing improvement included:

1. An increase in the number of attending staff

2. A decrease in user fees

The patient satisfaction results demonstrate a linear increase in the degree of satisfaction, which is consistent with the development of the QA programme.

Secondly it attests that clients are an important force in QA. (See Table 4.)

It is worth noting that the Q.A. process continues to develop. In the first quarter of the year 2000 , refining of the patient satisfaction instrument is already underway as $100 \%$ targets are being met. For instance the section on benefiting from the service has been broken down to specify the type of benefit e.g. physical or information on condition.

\section{Qualitative Results of QA Review:}

\section{Rehabilitation Staff}

Although tangible and objective results had been obtained to define the QA status for the Midlands province from the service record and client satisfaction points of view, staff often expressed other benefits that had not been demonstrated within the defined parameters of the QA instrument or patient satisfaction questionnaire. Group discussions during QA reviews were convened to identify these benefits.

Four themes emerged from the rehabilitation service providers as areas, which demonstrated the success of the QA programme.

- Staffs' clinical skills and knowledge improved compared to 1995

- Staff could easily detect problems that had not been apparent previously

- Staff felt that the QA programme made it easy for them to plan for clinical work

- Staff accepted and valued peer review sessions as a tool to facilitate their own professional development.

As a result of these positive outcomes the QA outline was adapted and included in the standard procedures manual for the Midlands rehabilitation departments. 


\section{DISCUSSION OF RESULTS}

The simple QA methodology outlined above solved problems that had been identified through the ZOPP analysis method.

It must be noted that the QA status for Gweru was higher than the QA status for the whole province. This difference was a result of:

1. Gweru's proximity to better-qualified rehabilitation and medical staff.

2. Larger numbers of rehabilitation staff members

3. As a result of the above two factors Gweru had closer monitoring systems

4. Access to more frequent and timely in-service training.

Further, in spite of the heterogeneity of the rehabilitation service providers, the variations in training levels and backgrounds, and differences in working experience the QA status achieved was extremely high. It is thus the submission of the authors of this paper that QA is implementable in a variety of situations even when the professionals involved have different backgrounds. The unifying factor to providing a quality service came through a common understanding and insight into the programme objectives. This was best achieved by participation of the different professionals in the process of problem identification, analysis and in working out solutions. The QA programme once developed was used as a tool and became instrumental in the whole process of monitoring quality.

The staff themselves expressed greater confidence in managing conditions they previously felt unsure of and lacked in confidence. The effect of the programme therefore did not just improve the quality of patient records but had the added benefit of raising the standard of assessment and clinical skills of those involved. Furthermore, the staff said they found it easy to identify problems and outcomes required in the planning process at an individual, departmental and programme level.

Deming (no date) outlines five factors in the process of QA programme development
- Defining the desired output (through analysis);

- Identifying the value creation process in the organisation;

- Modifying the existing system to get desired change;

- Committing top management to change process;

- Developing change concept.

Further one must acknowledge the components necessary for successful rehabilitation. These include, "a problemsolving interaction between client and therapist, based on systematic assessment, realistic goal setting, appropriate use of resources, and intelligent evaluation of outcomes..."(Bauer, 1989).

The process that led to the development of the Midlands Q.A. instrument and QA programme, demonstrates all of Demming's and Bauer's factors as outlined above. It also highlights the importance of understanding and committing to this change process by all stakeholders at every stage.

\section{CONCLUSION}

The success of the Midlands QA instrument development and the QA programme implementation is attributed to the participatory nature of the whole process. Although members initially viewed the process as a threat and only conformed in response to coercion, they developed a better understanding by participating in the programme. This resulted in a sense of ownership and professional gain.

Finally, it is important to realise that QA is one of the essential ingredients involved in the philosophy of a total approach to rehabilitation. As Bauer (1989) summarizes, "The focus is on the accountable delivery of a holistic service to people with problems; the emphasis is on the process rather than on the technical practice."

Clearly, rehabilitation service providers, rehabilitation patients and rehabilitation funding agencies stand to benefit from implementing QA programmes within rehabilitation services.

\section{ACKNOWLEDGEMENTS:}

The authors would like to thank the rehabilitation staff in the Midlands province, the Midlands Provincial Medical Directorate, and rehabilitation clients in the Midlands province for their work, support and cooperation in the ongoing process of QA instrument and programme development.

\section{REFERENCES}

Bauer D. 1989. Foundations of Physical Rehabilitation - A Management Approach. 1st Edition. Churchill Livingstone.

Blumenthal. 1997. The future of quality measurement and management in transforming health care system. Journal of the American Medical Association (19) 1622-5.

Cash's Textbook of Orthopaedics \& Rheumatology for Physiotherapists. Edited by P.A. Downie. 1984. Faber \& Faber

Cash's Textbook for some Surgical Conditions. 1979. Edited by P.A. Downie. Faber \& Faber.

Central Statistics Office - Zimbabwe. 1997

Deming WE. (No date). Principles for Quality: Deming's 14 points

http://deming.ces.clemson.edu/pubtqmbbs/ prin-pract/14pts.txt

Gesellschaft fur Technische Zusammenarbeit (GTZ). 1992. Objectives-oriented Project Planning, (ZOPP)

McRae R. 1983. Clinical Orthopaedic Assessment. 2nd edition. Churchill Livingstone

Midlands Province Health Information Department. Midlands Annual Profile 1997

Paeger A. 1997. Quality Improvement in Germany. Journal of Quality Improvement I(23)

Reerink E. 1999. Introduction, 1mplementation and Support of Quality Assurance and Improvement Programmes. Leadership Seminar for Quality Management in Health November 1999, Germany. 


\section{We'll organise everything for you.}

Bupa Healthcare Recruitment need

Physiotherapists \& Therapy Assistants

Throughout the UK

- Immediate start

- NHS \& private sector

- Short \& long term placements

- Temporary or permanent placements

- Top rates paid

- Flight paid

- Meet \& greet at airport

- Help \& advice on finding accommodation

- Travel arranged to your place of work

- Registration reimbursement

- Friendly, professional consultants

For more information call BUPA Healthcare

Recruitment on +442072816444 or email

bupa.hc.recruitment@lineone.net

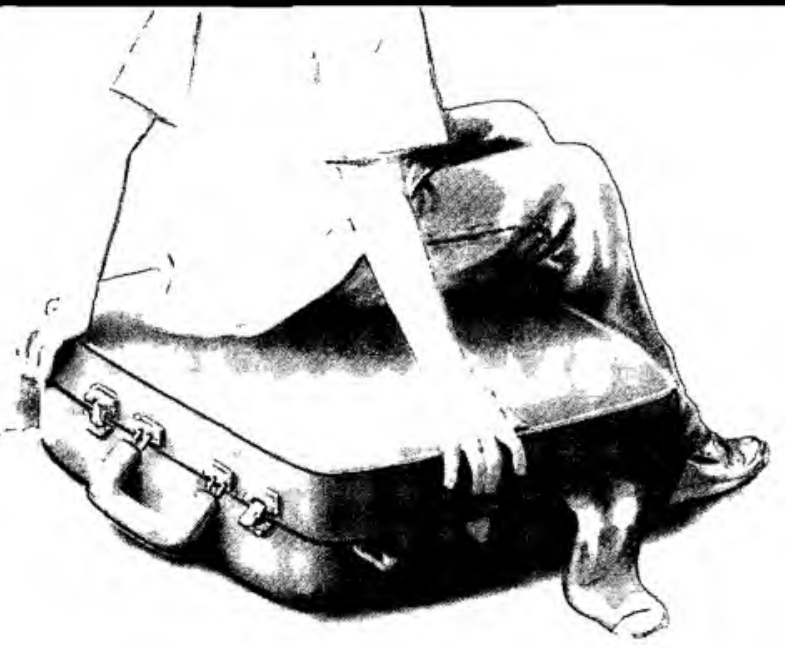

(Well, nearly.)

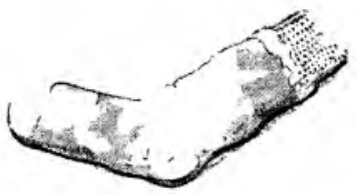

BUPA

Health Care

Recruitment
For the hottest work in the UK, taste what we have

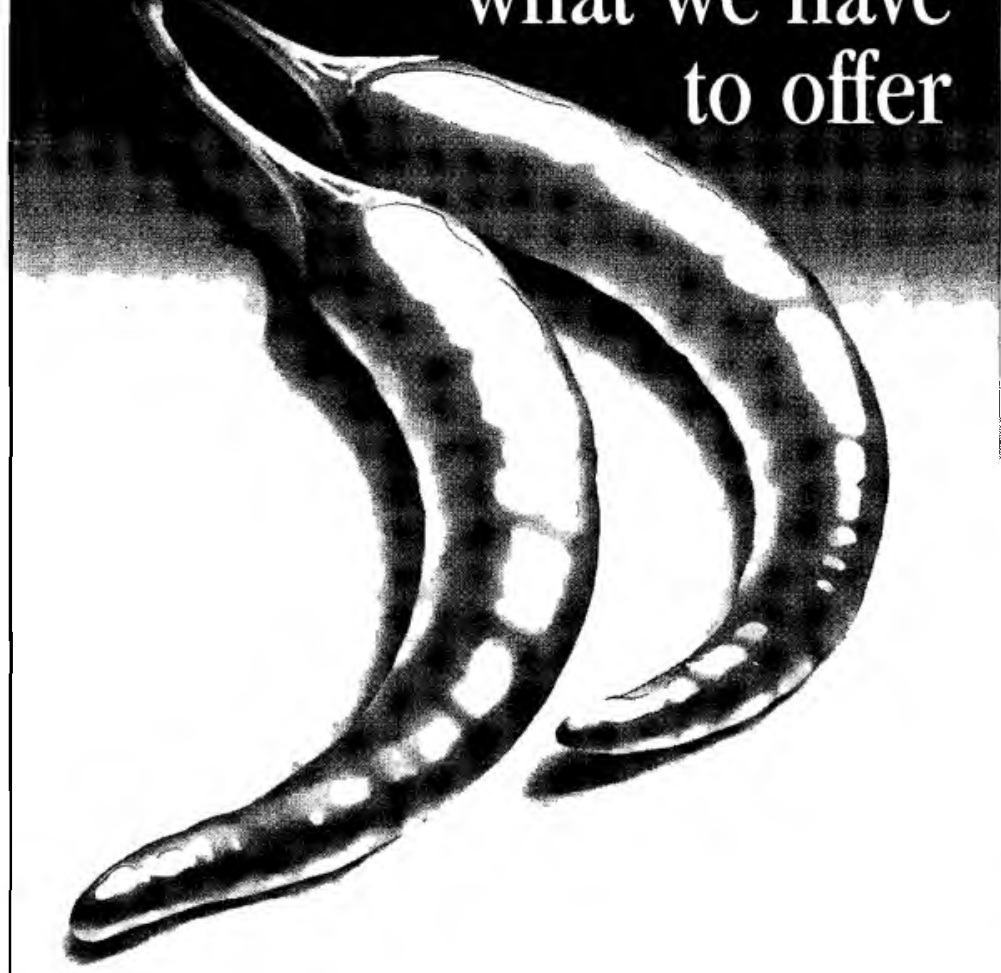

\section{Physiotherapists}

- Widest choice of Locum, Permanent and Fixed-Term Contracts

- Advice on:

State Registration

UK Visas and Work Permits

Accommodation

Bank Accounts

- Top rates of pay

- UK CPSM Registration Fees reimbursed

- FREE Holiday Pay

\section{Contact Bridget O'Farrell BScOT}

in South Africa on (021) 423-3853

Fax: (021) 423-3855

E-mail: corinth@mweb.co.za

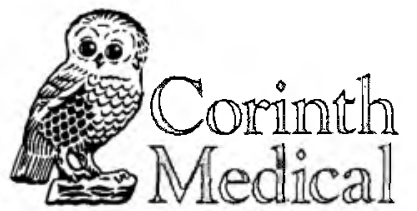

London Office

Toll Free 0800-99-3055 Fax: 09442082076894 E-Mail: pt@corinth.co.uk 